\title{
LAS VASIJAS Y SU POTENCIAL COMO SUJETOS \\ ESTABILIZADORES DE SERES INCOMPLETOS: PRÁCTICAS MORTUORIAS DE INFANTES DURANTE EL PERÍODO TARDÍO EN EL VALLE CALCHAQUí NORTE
}

\author{
Claudia Amuedo ${ }^{1}$
}

\section{* Introducción}

Las inhumaciones dentro de vasijas son uno de los fenómenos arqueológicos más extendidos en el noroeste argentino. En este trabajo se estudian los entierros de infantes en vasijas del período Intermedio Tardío en el valle Calchaquí Norte (provincia de Salta, Argentina). A partir de los análisis realizados sobre los contenedores cerámicos, las tapas y los restos humanos, pudo determinarse que los objetos participaron en otras actividades antes de formar parte de las tumbas, como tareas ligadas a la preparación de alimentos. Por el lado de los análisis osteológicos, se estableció el rango etario de los sujetos no mayor a tres años de vida. Con ello se pudo comprender que el contexto mortuorio es una combinación de elementos con caminos biográficos diferentes dentro los poblados prehispánicos: vasijas socializadas con amplios recorridos dentro de las casas, y niños que han fallecido antes de completar su integración a la comunidad. Estas trayectorias nos hablan de la constitución de la subjetividad en el pasado calchaquí, donde algunos pueden o no ser personas, tanto objetos como sujetos, al igual que sucede en otras ontologías no modernas, como la andina.

Palabras claves: infantes - vasijas - biografías - personas - ontología andina.

\begin{abstract}
Burials inside ceramic vessels are one of the most widespread archaeological phenomena in northwestern Argentina. In this paper we analyze infant burials in vessels from the Late Intermediate Period in the North Calchaquí Valley (Salta, Argentina). Analyses of the ceramic vessels, lids, and human remains enabled us to determine that the objects were used for other activities before entering the tombs, as tasks related to food preparation. The osteological analysis established the age of the subjects to be no more than three years at the time of death. This information indicates that the mortuary context is a combination of elements with different biographical trajectories within prehispanic settlements, such as socialized vessels with ample trajectories inside the dwellings, and children who have passed on before completing their integration into the community. These trajectories tell us about the constitution of subjectivity in past Calchaquí society, where some may or may not be people, both as objects and as subjects, similar to
\end{abstract} other non-modern Andean ontologies.

Key words: infants - vessels - biography - persons - Andean ontology.
Si bien es complejo trasladar ideas del presente al pasado, la lectura etnográfica y reflexión para su aplicación en arqueología es sumamente valiosa para acceder a niveles interpretativos cercanos a las experiencias y prácticas del pasado al generar una crítica de los supuestos culturales y teórico metodológicos del investigador. En el caso de estudio, es interesante notar que las prácticas mortuorias desplegadas en el momento de la muerte de un infante, durante el período Intermedio Tardío (900-1460 DC) en el valle Calchaquí Norte (provincia de Salta, Argentina), éstos recibían un trato diferente al resto de los sujetos mayores. Eran depositados individualmente dentro de vasijas y ubicados en los espacios residenciales (casas y patios) de los poblados conglomerados. Aquellos fallecidos en edades mayores eran inhumados fuera de las estructuras habitacionales, dentro de cistas ${ }^{2}$ utilizadas para alojar más de un individuo (Amuedo 2010: 141; Acuto et al. 2011).

Esto nos llama a reflexionar acerca de las diferencias existentes entre las categorías etarias y de persona que funcionaron en el pasado y aquellas que nosotros, como seres urbanos y postmodernos, manejamos cotidianamente. Por lo tanto, las preguntas que surgen del contexto mortuorio de infantes mencionado son las siguientes: ¿qué categorías se ponen en juego a la hora de enterrar a los niños menores de tres años?, ¿qué elementos significativos agregan los objetos estructurantes de los contextos mortuorios, la casa y las vasijas a la práctica funebria?

Una forma de deconstruir estas categorías en este trabajo es la lectura de etnografías realizadas en el área andina. Si bien los habitantes del paisaje andino encierran una

Recibido: Noviembre 2014. Aceptado: Febrero 2015

1 Instituto de Antropología de Córdoba (CONICET). Av. Hipólito Yrigoyen 174, Córdoba, ARGENTINA. Email: claudiaamuedo@gmail.com 2 Estructuras circulares de piedra con techo en falsa bóveda. 
multiplicidad de visiones del mundo y formas de explicarlo, la lectura de la etnografía de diferentes zonas distantes entre sí nos muestra que hay un sustrato compartido, elementos en común sobre la constitución y funcionamiento del universo. Dentro de esto, los niños como categoría social no existen tal y como los entendemos en la modernidad. Solo aquellas personas que pueden participar activamente dentro de las tareas de la comunidad son considerados sujetos sociales plenos (Fernández 2002). Por otro lado, como se ampliará a lo largo del trabajo, los pequeños que no pueden caminar, hablar o participar de los quehaceres cotidianos son considerados seres peligrosos e inestables desde el momento de su gestación, debiendo pasar por una serie de disciplinamientos y rituales de transformación para lograr ser seres completos. En este sentido, algunos objetos o elementos del paisaje integrados plenamente en las relaciones sociales de las comunidades, por inversión de energía e integración en las labores, son sujetos plenos. El cuerpo humano, como veremos, no determina la humanidad.

En este trabajo se consideran, en primer lugar, los aspectos teóricos relacionados con las nociones de cuerpo, y cómo este no determina necesariamente la existencia de una persona. Además, apunta a observar el potencial de subjetividad que pueden encerrar algunos objetos y como éstos pueden ser transformados en sujetos con agencia al igual que los humanos. Segundo, se discuten las nociones de persona en la ontología andina y los procedimientos que deben seguirse para que los cuerpos humanos puedan ser personas. Por ellos es importante discutir la categoría moderna de infancia a través del aporte de las etnografías andinas y su proceso de construcción de personas o sujetos sociales. Tercero, se describirá el emplazamiento de los contextos mortuorios, las vasijas y los otros elementos estructurantes de las tumbas, junto con los análisis realizados para determinar el rango etario de los sujetos inhumados (Amuedo 2012, 2014). Por último, se plantea considerar la conjunción de vasijas e infantes en tumbas ubicadas dentro de las casas, como una forma de establecer el control sobre sujetos ontológicamente diferentes.

El objetivo es mostrar una fase de la constitución de un ser en "persona" en las poblaciones prehispánicas del valle Calchaquí, tanto para humanos como para no humanos. Con esto busco, primero, demostrar cómo los contenedores cerámicos fueron elementos que dentro de su historia en el ámbito doméstico pudieron ser transformados en sujetos activos consustanciados con las actividades cotidianas y los habitantes de las casas, para luego ser intermediarios en la relación entre los infantes muertos y los vivos. Asimismo, intento ampliar el concepto de comunidad, incluyendo en ésta no solo a los humanos, sino a otros elementos constituyentes de la vida, como lo son los objetos.

\section{Los objetos como sujetos}

La composición de las entidades que diferentes ontologías detentan nos muestra constantemente una fisicalidad (cuerpo) e interioridad (alma-espíritu-razón), como bien lo ha desarrollado y ejemplificado Phillipe Descola (2012). El dualismo cuerpo y alma de la modernidad se justifica dentro de esta división.

La idea del alma y el cuerpo como elementos opuestos es anterior a la modernidad, aunque en el pensamiento occidental tiene su mayor penetración a través del cristianismo. Desde los postulados religiosos, el cuerpo se transforma en una especie de idea incompleta, que no alcanza la perfección, un problema a resolver y el centro de las debilidades del hombre y la mujer. Esta separación entre lo etéreo y lo material es retomada por el positivismo, particularmente en las reflexiones de Descartes, separando la materialidad de la mente, en sintonía con los postulados que separaron a la naturaleza de la cultura. La mente es el reino de la cultura y desde allí es donde se comprende al mundo, abordado a través de la razón. A través de esta idea, el cuerpo deja de ser una entidad que conecta simbólicamente al ser con el entorno que trasciende al sujeto como unidad, sino que es en su individualidad (Le Breton 2002). El cuerpo moderno contiene a una persona como una entidad separada, producto de procesos internos, y por lo tanto, susceptible de ser controlado por las estructuras mentales.

La evidencia de que el cuerpo en la modernidad, tal y como se ha explicado, es el resultado de un momento histórico particular y no preceptos universales está dado por la etnografía. Según los trabajos etnográficos analizados por Descola (2012), el cuerpo no es entendido necesariamente por las sociedades no occidentales como separado del mundo o de los otros sujetos, los límites de 
éste, como los límites de las subjetividades, no son los mismos que los postulados por la modernidad. Más allá de demostrar los puntos en común entre varias sociedades, donde la humanidad trasciende a la especie humana y es definida por las relaciones entre seres que habitan el mundo (Descola 2012: 56), lo que intenta este autor es hacer evidente el corte tajante que Occidente provoca al definir a la humanidad por la sustancia corporal que la contiene. El cuerpo y ser no necesariamente coinciden, ya que el sujeto puede trascender sus límites y habitar objetos, otros sujetos y reproducirse en la relación que estos tienen entre sí, más allá de su agencia o poder. También otras agencias, sobre las que no tiene control, hacen actuar al sujeto, ya que la acción se distribuye entre agentes que no son necesariamente siempre humanos (Latour 2008: 79).

Nuestra disciplina, la arqueología, como ciencia moderna, no fue ajena la separación ontológica moderna entre el cuerpo y la mente. La existencia de esta división se definió por la presencia de un espíritu dominador, distante y soberano de las cosas y los cuerpos (Merleau-Ponty 2008 [1948]). En el dualismo cartesiano, los objetos y el cuerpo (materiales) son epifenómenos de la mente (inmaterial) (Malafouris 2008). Lo material es, en este sentido, un problema a resolver para abordar la realidad y llegar a la verdad. La percepción a través del cuerpo es un espectáculo de la carne, una realidad vista a través de fantasías sensibles (Merleau-Ponty 1957, 2008 [1948]), transformándose en un vehículo de las representaciones sociales (carne, vestido, objetos, espacio, etc.) (Joyce 2005). Por ello es que debemos discutir las concepciones clásicas aún utilizadas, donde los objetos no son más que un simple fenómeno secundario derivado del proceso social, el reflejo directo y estático de la organización social, tal como una tumba, un monumento, la sofisticación artesanal, como la representación de las creencias e ideas mentales, en cuanto vehículo o telón de fondo para el despliegue de las prácticas sociales (Joyce 2005; Alberti 2007).

En este trabajo se considera la relación sujeto-objeto como una relación dialéctica, de construcción mutua (Gastaldi 2010). Por lo tanto, la representación no precede a la producción del objeto, sino que los materiales y los sujetos establecen un diálogo, una negociación y transformación mutua que dará como resultado un ob- jeto (Ingold 2000, 2010). Ya que es en "el hacer" donde se van incorporando los sentidos, donde se condensan y reúnen diferentes aspectos de la realidad social (Lemonnier 1992). Pero este proceso no se detiene, sino que en las prácticas sociales donde se activan las relaciones objeto-objeto y objeto-sujeto, estos van a reproducirse, reafirmarse o modificarse (Gastaldi 2010). El resultado de esta relación es una materialidad particular, entendida como una red de objetos con una configuración espaciotemporal históricamente producida y en relación dialéctica con las prácticas y categorizaciones de una sociedad en particular (Acuto 2008).

Ahora bien, la pregunta es icómo consideramos la posibilidad de que los objetos puedan ser sujetos activos? Y en este sentido, ¿cuál es la idea de sujeto o persona que consideramos para poder trazar el puente dentro de la dualidad ya comentada?

Cuando hablamos de personas o sujetos activos debemos considerar las advertencias que hace Viveiros de Castro (1986), quien plantea que es un error postular el principio de autonomía como definición de la persona, ya que el individualismo como principio, la búsqueda interna del "yo", tiene un anclaje histórico ligado a nuestra sociedad moderna. Desde el perspectivismo, el multinaturalismo del pensamiento amerindio discute la existencia de una única naturaleza interpelada, recortada e interpretada por múltiples culturas. Existe más bien una cultura, una humanidad, un tipo de ser persona cruzada por varias naturalezas. Es decir, un mismo concepto de persona/ humanidad habitando múltiples cuerpos (humanos, animales, vegetales, minerales, etc.). El sujeto, la persona, es el resultado inestable de un proceso preformativo, donde las prácticas, los gestos, las palabras, los objetos crean el cuerpo y la identidad del sujeto.

Como dije, Phillipe Descola (2012) plantea como universal la dualidad entre interioridad y fisicalidad (cuerpo), lo que varía son los vínculos entre estas. Según este antropólogo, dentro del esquema de naturaleza manejado en Occidente, los únicos portadores de interioridad son los cuerpos humanos, dejando al resto del universo en el plano de la naturaleza. Sin embargo, esto no sucede en otras ontologías descriptas por el mismo autor. Descola plantea que el naturalismo, nombre que recibe la ontología moderna, es contingente, producto del devenir histórico 
y una cosmología entre muchas otras que la historia de la humanidad ha dado (Descola 2012: 144). Además del naturalismo, Descola $(2006,2012)$ propone tres ontologías generales más: animismo, totemismo y analogismo. Me centraré sobre esta última ya que se corresponde con el pensamiento andino.

El analogismo, como uno de estos esquemas, muestra una correspondencia con la cosmología andina al considerar las nociones de fisicalidad e interioridad con las de continuidad y discontinuidad entre entidades. En ella observamos una verdadera proliferación de entidades discontinuas y singulares, tanto en el plano de las fisicalidades como de las interioridades (Descola 2012: 310). De esta manera tenemos una proliferación de singularidades, con morfologías diversas pero ordenadas entre sí a partir de redes de correspondencia que permiten ordenarlas. Si bien cada ser es particular, un elemento de su existencia será compartido con otro, estableciendo verdaderas cadenas de analogías. Todos los seres serán por último parte de un colectivo más inclusivo, superador de lo puramente humano, como veremos a continuación.

\section{Ser persona dentro de la ontología andina}

Si bien los habitantes del paisaje andino encierran una multiplicidad de visiones del mundo y formas de explicarlo, la lectura de la etnografía de diferentes zonas distantes entre sí nos muestra que hay un sustrato compartido, elementos en común sobre la constitución y el funcionamiento del universo. Existe, por ejemplo, un culto extendido a los cerros. Ahora bien, las prácticas y formas de desplegar ese culto varían regionalmente: como muestra Gabriel Martínez (1989), algunos pueblos suben a los cerros, para otros el ascenso está vedado, así como el establecimiento de las jerarquías entre ellos varían.

En los Andes, la praxis se despliega entre una multiplicidad de entidades singulares y autónomas que pueblan el universo (Martínez 1989: 23). Dentro de los esquemas propuestos por Descola (2006), el analogismo es el que mejor encajaría con esta realidad, donde las discontinuidades entre entidades no son rígidas, sino más bien dinámicas y permeables en algunos casos. Siguiendo esta idea, me interesa recopilar algunos ejemplos de la etnografía y la etnohistoria andina. Con esto busco deconstruir nuestra concepción de la naturaleza y las ideas de cuerpo y persona, intentando abordar eventualmente las mismas ideas, pero desde un paisaje más afín a lo que se quiere comprender.

Siguiendo los trabajos de Cavalcanti-Schiel (2007), las subjetividades son construidas dentro de relaciones de intercambio de esfuerzo entre los muchos y diferentes sujetos que conforman el cosmos. La persona subordinada, individualizada y gestada desde la autonomía y el pensamiento no forman parte de la tradición andina. Todos los elementos del cosmos tienen el potencial de ser "personas", pero este estatus es construido en su inserción dentro de la red de relaciones con los otros seres. Esta red de vínculos entre agentes subjetivos diferentes, como animales, plantas, elementos del paisaje, objetos, humanos, vivos y muertos, así como también relaciones entre entidades no visibles, permiten la reproducción de la vida, la circulación de los flujos vitales, el ayni (Earls y Silverblatt 1978), a través de acciones de intercambio de energía, el cuidado mutuo y la transformación de elementos según el potencial interno de cada sujeto y la naturaleza de su relación.

El esfuerzo como concepto es considerado también por Gabriel Martínez (1989) como fundamental para la reproducción del mundo. En su caso, los humanos "sostienen" con "esfuerzo" a través de los cultos y la crianza de animales y vegetales la reproducción de la fuerza vital del mundo (Martínez 1989: 65-66). Es en el vínculo con las entidades que conforman el paisaje, en el esfuerzo por producir, que ambos - humanos y no humanos - mantienen la vitalidad del universo. Es por ello que la dualidad naturaleza y cultura se diluye en esta relación entre "personas" portadoras de humanidad, pero con diferentes corporalidades.

Este es un buen ejemplo, entre muchos otros, de que los sujetos se constituyen en función de las relaciones sociales que establecen con las entidades que habitan el mundo, ya sean humanas ono humanas (Martínez 1989; Bastien 1996; Allen 1998; Cavalcanti-Schiel 2007). La persona no goza de autonomía, tal y como lo comprendemos dentro de las sociedades occidentales y modernas, sino que está íntimamente ligada a la comunidad a través de relaciones equilibradas. La persona individual se define en términos de una red socioritual de conexiones entre parientes, lugares sagrados, animales, vegetales y 
herramientas domésticas (Allen 1998:23). Por lo tanto, el ser se construye en su función de nodo, manteniendo el equilibrio en la serie de relaciones. El cuerpo de una persona no encuentra sus límites físicos donde termina su piel, sino que es capaz de conectarse con otras personas, aquellas con las que tiene conexiones intrínsecas para, por ejemplo, ligar sus estómagos y compartir alimentos (Allen 2008: 199; Pazzarelli 2009; Acuto et al. 2011; Amuedo 2014).

La base de todas las relaciones entre diferentes subjetividades dentro de la ontología andina, sin embargo, es la inestabilidad de los pactos entre los sujetos con la necesaria reactualización cíclica de los lazos (CavalcantiSchiel 2007). Los favores entre entidades no son gratuitos e implican riegos, son parte de una relación compleja, cuyo equilibrio debe ser sostenido (Martínez 1989:64). Por ejemplo, las relaciones de reciprocidad entre los vivos y los muertos implican la alimentación mutua, los vivos ofrecen alimentos a los muertos y los últimos ayudan al crecimiento de los animales y los cultivos para alimentar a los vivos (Amuedo 2014). Además, hay seres cuya potencia es inestable y puede ser dañina si no es controlada por medio de tabúes o rituales específicos que permitan intervenir el flujo de esa energía de manera constructiva o destructiva. Estos rituales incluyen en la mayoría de los casos la alimentación, incluyendo dentro de la comensalidad la ingesta de bebidas y el consumo de hojas de coca.

Dentro de este esquema, algunos objetos del mundo material tienen el potencial de oficiar como intermediarios, y por lo tanto darle razón ontológica dentro de los complejos intercambios de energía (Cavalcanti-Schiel 2007). En esta línea trazaré la relación entre los infantes muertos y las vasijas funerarias para los momentos preinkas del valle Calchaquí Norte.

\section{Transformarse en persona dentro de la ontología andina}

Un punto interesante que me gustaría discutir brevemente es que la categoría de infancia no es transhistórica como tampoco lo es la de persona. Es importante comprender que la infancia como categoría tiene una gama de diferentes significados dependiendo del contexto social (Finlay 2000). Por ejemplo, Inge Bolin (2006), en sus estudios sobre la infancia en las comunidades actuales de pastores de gran altura de los Andes, concluye que los niños de Chillihuani (Perú) no tienen infancia. Ellos participan en el mundo adulto desde una temprana edad. No existe una cultura material de la infancia ni tampoco cuentos o canciones infantiles (Bolin 2006).

El niño andino, a diferencia de nuestra concepción moderna, no es considerado persona hasta no estar integrado por completo a la comunidad, como sujeto activo dentro de las prácticas, quehaceres y normas sociales del mundo de los no infantes (Fernández 2002). Estos ritos involucran transformaciones en los cuerpos, como el primer corte de cabello, que lo van moldeando como persona para pertenecer a la comunidad. La ambivalencia de la identidad del niño es vivida desde el momento de la gestación. Su cuerpo no es dado, sino construido dentro de un proceso preformativo en el habitar y a través de ritos específicos.

En el caso de las actuales comunidades aymaras de Potosí, la transformación de niño en persona se da a través de una serie de eventos o ritos de pasaje, como la concepción, el parto y la rutucha, que se detallará más adelante. Al nacer no es considerado un sujeto, sino un ser voraz que batalla a muerte con la parturienta. Esto está relacionado con la sangre implicada en su formación y alimentación. En el momento de la concepción, la sangre se mezcla con el semen, considerado como una suerte de sangre blanca, y coagula (Platt 2002) ${ }^{3}$, formando al feto. Éste es alimentado en el útero con sangre a través de pequeñas "tetas" que desarrolla la placenta (Arnold y Yapita 2002), y en algunos casos la voracidad puede llegar a poner en peligro la vida de su madre (Platt 2002). Por otro lado, su género se establece dentro de la vida intrauterina, el feto masculino es sólido desde su origen, mientras que el femenino de sangre, es líquido y suave (Arnold y Yapita 2002), pero no es determinante para definir su cuerpo. Solo se trata de un ser con la "potencialidad ontológica de ser persona" (sensu Viveiros de Castro 2011: 36).

El momento del parto es visto como una batalla entre la madrey su voraz feto, homólogos a un guerrero ysu enemigo, quien es finalmente expulsado. Luego es disciplinado,

3 Este evento es homologado con la producción de quesos, con la coagulación de la leche, y también con la producción textil, con el hilado de la sangre en el interior del útero a través de las contorsiones del cuerpo. 


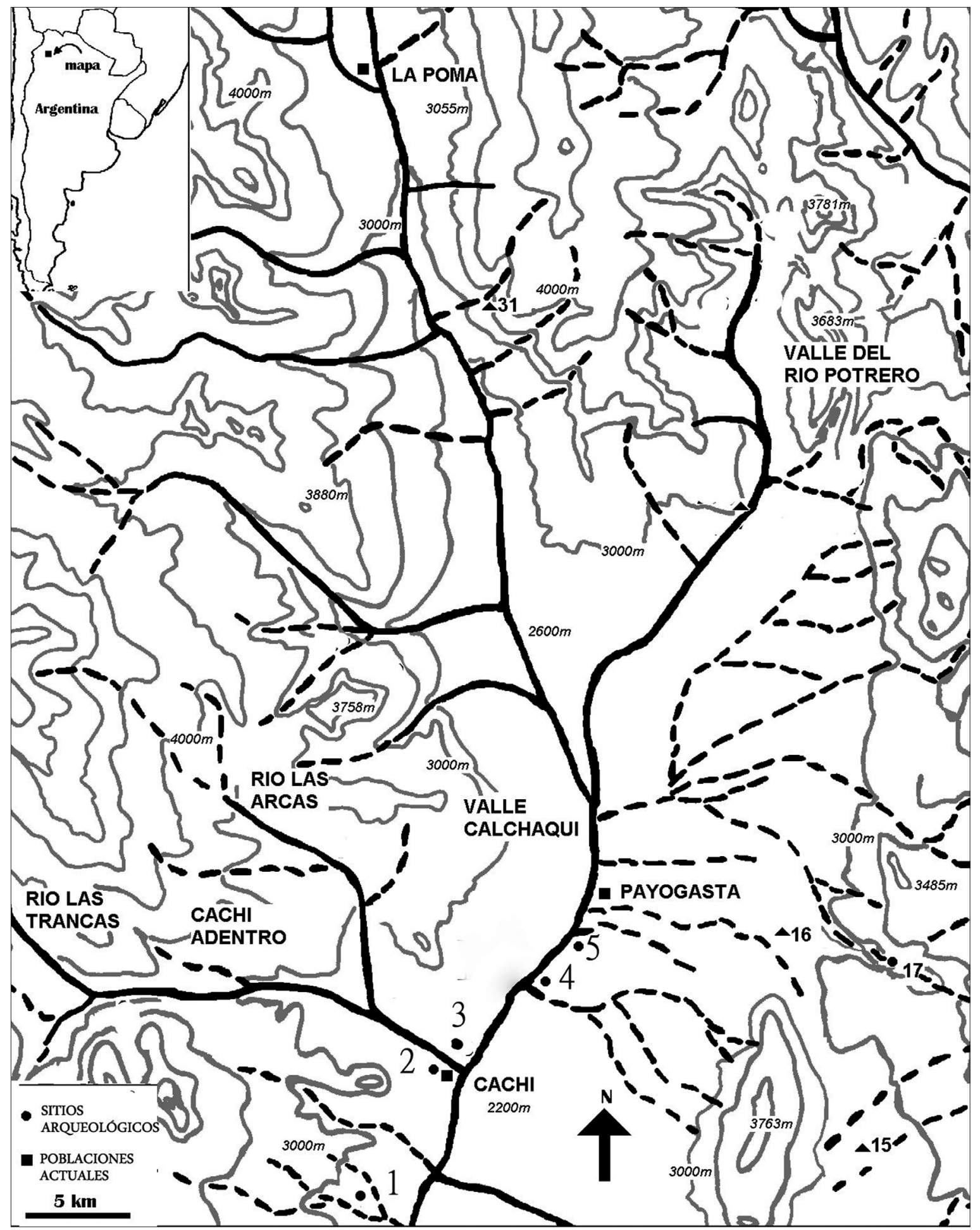

Figura 1. Valle Calchaquí Norte: 1) La Paya (SSalCac 1), 2) Tero (SSalCac 14); 3) Mariscal (SSalCac 5), 4) Kipón (SSalCac 3) y 5) Ruiz de los Llanos (SSalCac 10). 
y en un primer momento no es alimentado por todo un día para calmar su hambre, considerado como primer acto de sociabilización. Luego de múltiples formas de vestimenta, limpiezas y restricciones (ver Platt 2002; Spedding 2008) se realiza la rutucha, celebrada cuando el niño ya camina o habla, no antes de los tres años de edad (Van Vleet 2008). Esta ceremonia, registrada en comunidades actuales andinas (e incluyendo mis propias observaciones en el valle Calchaquí), consiste en el primer corte de pelo del niño realizado por los miembros de la comunidad. Antes de esto, la cabellera no es cuidada ni peinada, específicamente sin peinados ni formas que distingan género. Cada participante corta un mechón y paga por él con dinero. El producto final de la ceremonia es la introducción del niño en la comunidad, en la vida económica y productiva, como así también se materializa en el peinado la diferencia entre géneros (Spedding 2008).

Sin embargo, cuando el niño muere en medio del proceso, sin completar su incorporación a la comunidad, éste se vuelve peligroso, sobre todo para las mujeres. Su voracidad no aplacada, buscará la sangre de las parturientas, quienes corren serios peligros de muerte en manos de estos seres incompletos (Arnold y Yapita 2002; Platt 2002). O como en el caso del valle Calchaquí, los niños no bautizados regresarán en forma de duendes a penar o maltratar con fuertes golpes con su mano de lana a las madres respectivas o a la familia que lo ha abandonado. El bautismo cristiano en este caso es la forma de incorporar al ser a la comunidad, de estabilizarlo.

Sin extrapolar lo visto, estas ideas nos llevan a reflexionar sobre las categorías que se ponen en juego a la hora de inhumar los restos de niños por parte de los pobladores norcalchaquíes actuales. Por ello, veremos a continuación los resultados de los análisis relacionados con el emplazamiento de los contextos mortuorios, su estructuración y el rango etario que estamos manejando en este tipo de práctica.

\section{* El entierro de niños en vasijas}

El valle Calchaquí Norte se ubica en la provincia de Salta, en el noroeste de la República Argentina (Figura 1). Es un valle longitudinal que corre de norte a sur, siguiendo el recorrido del río Calchaquí. El valle tiene una extensión aproximada de $200 \mathrm{~km}$ de longitud, con menos de 100 $\mathrm{km}$ para el sector norte. Sus líneas fundamentales están dadas por dos cordones montañosos paralelos con alturas máximas de $6382 \mathrm{msnm}$ (cerro Libertador). El fondo del valle, donde se encuentra la gran mayoría de los poblados conglomerados del período Intermedio Tardío, se ubica a una altura de $2300 \mathrm{msnm}$ aproximadamente. El sector norte se extiende desde las inmediaciones de la localidad de La Poma y su límite sur está, según las fuentes citadas por Lorandi y Boixádos (1987-88), en el pueblo de Atapsi, cercano a Seclantás.

En los últimos años, la caracterización clásica del período Intermedio Tardío, ha sido cuestionada (Nielsen 2006; Albeck y Zaburlín 2007; Acuto 2008), criticándose tanto los modelos teóricos empleados para sostenerla, como la falta de evidencias sustanciales acerca de la complejidad sociopolítica y la desigualdad que el registro arqueológico de varias regiones exhibe.

Dentro de esta línea, Acuto (2008) sostiene que la materialidad y la espacialidad de las personas que habitaron durante el período Intermedio Tardío el noroeste argentino creaban un sentido de integración, conocimiento y articulación, o comunalidad, inhabilitando la mayoría de las tendencias que pudieran llevar hacia la desigualdad y la estratificación institucionalizadas. Esta conclusión surge de un enfoque centrado en las experiencias y las relaciones cotidianas que las poblaciones prehispánicas construyeron en el habitar los paisajes, en la materialidad y espacialidad construidas en éste.

Dentro de esta mirada del mundo doméstico y cotidiano de los pobladores prehispánicos, la norma del habitar en un poblado era la redundancia material, la articulación e integración. Habitar un poblado del valle Calchaquí Norte, a partir de los resultados obtenidos en nuestras investigaciones, no difería de esta mirada. La redundancia es el sustrato que recorre a todas las observaciones emprendidas: todos residían en casas de arquitectura y diseño similares, empleaban y consumían los mismos tipos de bienes, decoraban sus objetos con los mismos motivos, y enterraban a sus muertos en tumbas y vasijas de iguales características, sin existir tampoco marcadas diferencias en los objetos ofrendados (Acuto et al. 2011). Los residentes de los poblados conglomerados bajo estudio no habitaban un paisaje fragmentado y jerarquizado, 
sino todo lo contrario, las experiencias cotidianas estimulaban un sentido de semejanza y unidad dentro de la comunidad (Acuto et al. 2008).

En este contexto, la inhumación dentro de vasijas es una de las prácticas mortuorias más comúnmente registrada para momentos prehispánicos en el noroeste argentino, con una amplia continuidad histórica en el norte del valle, ya que existe evidencia de ella desde el Formativo (200 AC a 950 DC) hasta momentos inkaicos (Ambrosetti 1907; Díaz 1978-84; Tarragó 1980). Sin embargo, para momentos tardíos, el tipo de práctica relacionada con las inhumaciones de niños en esta región ha sido generalmente descuidada, tratándola como parte del universo de las personas adultas (Tarragó 1994), o considerando su continente cerámico por separado. Esto último se relaciona con los abundantes trabajos que existen sobre las urnas decoradas de diversos estilos tales como santamarianos, Loma Rica, Belén, entre otros (Podestá y Perrota 1973; Baldini 1980; Caviglia 1985; Velandia Jagua 2005; Marchegiani 2008; Nastri 2008; Nastri y Stern 2011, entre otros). Estos trabajos mencionan los usos de las vasijas en contextos mortuorios, sin profundizaren el universo de la práctica funebria.

Pese a estas críticas, es destacable la serie de trabajos emprendidos por Lidia Baldini e Inés Baffi (Baffi et al.2001; Baldini y Baffi 2003, 2007a, 2007b) sobre entierros de infantes en contenedores cerámicos, quienes han presentado una serie de trabajos en los últimos años llamando a la reflexión sobre el registro de entierros de niños en vasijas en el valle Calchaquí, y sobre las motivaciones y las prácticas sociales relacionadas con ellos (Baffi et al.2001; Baldini y Baffi 2003, 2007a, 2007b). Estas autoras han profundizado sobre todo en la inhumación dentro de "vasijas de uso doméstico en sitios tardíos" en la zona del valle Calchaquí (Baldini y Baffi 2007b), sin considerar aquellas decoradas del tipo santamariano. Las autoras proponen que este tipo de vasijas toscas fueron utilizadas previamente para otro tipo de actividades y luego para el entierro de niños. Si bien la propuesta es interesante, el uso previo de los contenedores cerámicos es asumido pero no demostrado, tanto por Ambrosetti (1907), Díaz (1978-84) y Baldini y Baffi (2007). La presencia de hollín en las paredes externas es la evidencia más clara para establecer un uso previo y por encontrarse, en algunos casos, en el interior de recintos dentro de los poblados conglomerados (Baldini y Baffi 2003, 2007a).

En el valle Calchaquí Norte se han documentado numerosos hallazgos de entierros de niños en contenedores cerámicos (Ambrosetti 1907; Díaz 1978-1984), de los cuales se analizaron para este trabajo 75 contextos mortuorios de manera completa (Amuedo 2010:187). Según la evidencia, las inhumaciones se realizaron en el interior de vasijas decoradas (urnas santamarianas, urnas santamarianas de "tres cinturas", y ollas globulares decoradas) o del tipo utilitario (vasijas globulares) (Figura 2). Estos enterratorios se encuentran diseminados en el interior de los sitios conglomerados y también por fuera de éstos, en áreas de cementerio.

De estos hallazgos — se destacan en la zona de estudio y son retomados en este trabajo - los realizados por Juan Bautista Ambrosetti (1907) en La Paya, Salvador Debenedetti (1908) en Kipón, Pío Pablo Díaz y colaboradores en Tero y La Paya (Díaz 1978-84, 1981; Tarragó et al. 1979), y en el sitio Ruiz de los Llanos, por Lidia Baldini e Inés Baffi (Baldini et al. 2001). Además de los efectuados por nuestro equipo de investigación en el sitio Mariscal.

De los análisis realizados sobre la muestra mencionada, que veremos en detalle a continuación, podemos adelantar que se trata de un tipo de sepulcro destinado exclusivamente a niños menores de tres años, incluyendo mortinatos y neonatos, y que se realizaba dentro de vasijas de diferentes tipos cerámicos, tapadas y alojadas en su mayoría dentro de las casas y patios de los poblados conglomerados.

\section{Localización y estructuración de los contextos mortuorios}

Localización. Los poblados conglomerados correspondientes al período Intermedio Tardío (900-1470 DC) del valle Calchaquí Norte están emplazados, en su mayoría, en el fondo del valle sobre las primeras terrazas del río. Los sitios se encuentran en las cercanías de las áreas más fértiles del valle, asociados a zonas de cultivo. Éstos se caracterizan por componerse de múltiples recintos semisubterráneos, de tamaños variables, adosados entre sí por muros compartidos siguiendo un patrón celular.

El material sobrante de las excavaciones de las estruc- 
turas fue utilizado para construir las vías de circulación y los montículos que las articulan. Los montículos, en este sentido, funcionaron como nodos de las sendas que recorren los sitios, actuando como bisagras entre sectores diferentes dentro del mismo poblado. Dentro de los sitios, y particularmente en el interior de los recintos, se registran una serie de actividades básicas relacionadas con tareas domésticas y de subsistencia. Éstas son: procesamiento, almacenamiento, cocción y consumo de alimentos y bebidas; producción de variados artefactos, tal como cerámica, instrumentos líticos, textiles y metalurgia (Acuto et al. 2008, Amuedo 2010).

La localización de las tumbas de infantes en los sitios mencionados muestra una tendencia a favor del emplazamiento dentro de los poblados conglomerados (85,3\%), con solo un $14,7 \%$ ubicado en áreas de cementerio ( $\mathrm{Fi}$ gura 3). Es decir, de la muestra general de 75 casos, 64 se encontraron al interior de los sitios.

Considerando los entierros en el interior de los sitios, las tumbas se ubicaron cercanas a los muros y/o en los ángulos de los recintos, con las bocas emergiendo de los pisos de ocupación. En el caso de los trabajos de Ambrosetti (1907) en La Paya se menciona este tipo de datos, aunque de una manera no sistemática. En Kipón tampoco existe la observación sistemática, aunque puede inferirse del croquis presentado por Debenedetti (1908). Para el resto de los sitios este dato es preciso.

De un total de 75 casos, el 70,7\% (N53) de los hallazgos están alojados dentro de los contextos residenciales, ya sea dentro de patios o en habitaciones techadas. Se observa, por lo tanto, una fuerte correlación entre los complejos residenciales y las tumbas de infantes que debe ser tenida en cuenta en relación a otros lugares también utilizados para inhumar, como por ejemplo los montículos. Estos últimos son mencionados en la bibliografía de la zona como los lugares predilectos para las inhumaciones (DeMarrais 2001), aunque solo representan el 2,7\% de la muestra.

En la parte más elevada de los montículos que funcionan como nodos, con más espacio y algunos con mayor altura, hemos observado en la recorrida de los sitios, el emplazamiento de cistas, muchas de ellas violentadas por saqueadores, aunque es muy dificultoso detectar en superficie los posibles saqueos de vasijas. Aun así, y basándome en la evidencia disponible, los montículos fueron una de las opciones para emplazar las tumbas de niños, pero no la más frecuente, sino que fue utilizada excepcionalmente ( 2 de 75$)^{4}$. En el caso de las vías de circulación monticulares solo se halló emplazada una tumba. Se trata del caso de Ruiz de los Llanos (Baffi et al. 2001; Baldini y Baffi 2003, 2007a, 2007b), resultado de una excavación de rescate y no se cuenta con más información de otros sectores del sitio. Aun así, es un importante ejemplo de un entierro ubicado en un montículo alargado. Por otro lado, dentro de los caminos internos se encontró solo una tumba, la 5=150-1-O1 de Mariscal, ubicada del lado externo del muro este del recinto 150.

Son pocos los casos de tumbas de infantes en áreas de cementerio. En la necrópolis de La Paya se ubicaron solo $14,7 \%$ ( $\mathrm{N}$ 11) de entierros en vasija, la gran mayoría pertenecientes al sitio La Paya ${ }^{5}$.

En conclusión, los datos muestran una tendencia que indica la preferencia por los lugares cerrados y de mayor privacidad, especialmente al interior de los complejos residenciales de acceso restringido al grupo familiar, por sobre sectores de mayor exposición pública.

Contenedores cerámicos. Como ya se dijo, la muestra está compuesta por 75 contextos mortuorios, por lo tanto son 75 las vasijas consideradas. Éstas corresponden a cuatro tipos (véase Figura 2), entre los cuales se puede destacar que más de la mitad de los entierros, un 54,6\% $\left(\mathrm{N}_{41}\right)$ se realizaron dentro de vasijas toscas. Del universo de la muestra, las urnas santamarianas suman el 29,3\% (N 22), llegando a un 40\% (N 30) si se agregan las urnas santamarianas de "tres cinturas" (N 8). Las ollas globulares decoradas fueron utilizadas con menor frecuencia: solo un $4 \%\left(\mathrm{~N}_{3}\right)$ (Figura 4 ).

4 Uno de los casos es el Hallazgo 10 de Kipón. El contenedor con el cuerpo de un infante fue hallado dentro de una cista con los cuerpos de nueve adultos (Debenedetti 1908:30). El otro de los hallazgos es el E14 del sitio Tero:una vasija calzada con rocas dentro de un hoyo sobre un montículo (Díaz 1978-84).

5 Esta zona, definida por Ambrosetti, presenta concentraciones de cistas en un área en la que hemos observado la presencia de varias estructuras habitacionales con características similares a las estructuras internas del poblado. 


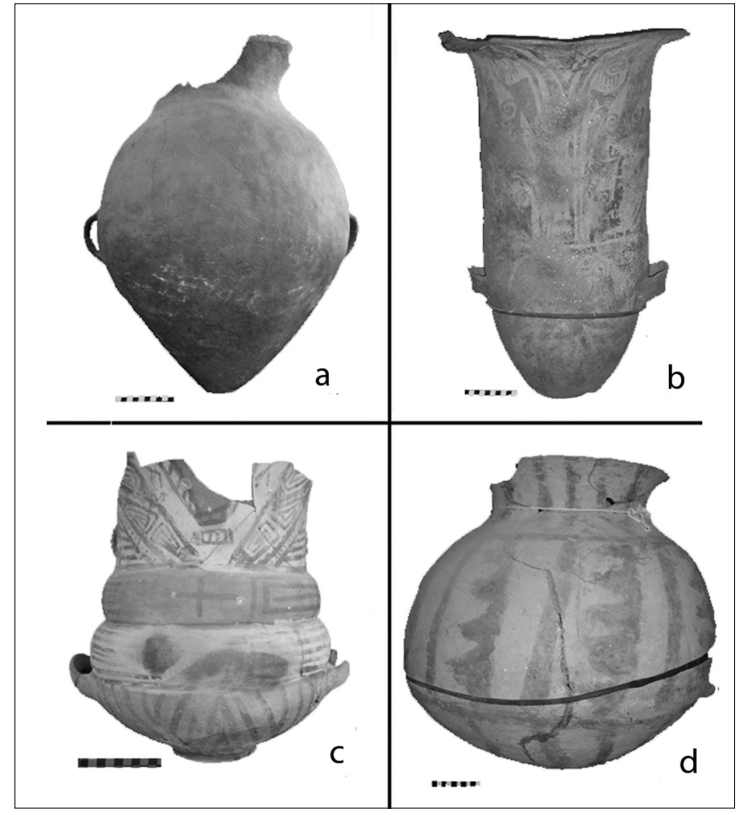

Figura 2. a) Vasija tosca, b) Urna Santamariana, c) UrnaSantamarianaTres cinturas, d) Olla globular decorada.

Con el fin de determinar si las piezas estuvieron involucradas en otras actividades antes de ser utilizadas para contener los cuerpos, así como comprender los significados que encarnaban los distintos tipos representados, como primer paso se buscó demostrar si éstas fueron o no fabricadas especialmente para el ritual fúnebre. Para esto se indagó sobre las evidencias de usos previos en los contenedores utilizados en los entierros y se compararon con recipientes cerámicos similares hallados sin restos humanos. Como segundo paso, una vez demostrada su no exclusividad para uso fúnebre, se apuntó a establecer

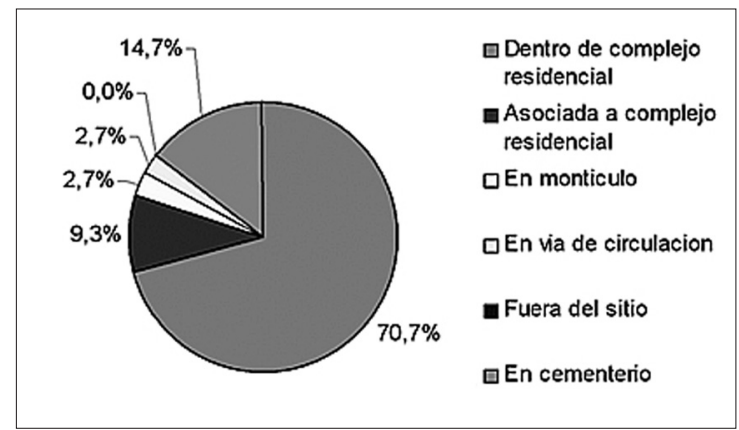

Figura 3. Distribución de la localización de los contextos mortuorios de infantes. en qué contextos se usaban y con qué tipo de prácticas y relaciones sociales se condensaron dentro de su biografía en la convivencia con los habitantes norcalchaquíes.

Se realizaron dos tipos de análisis sobre cada tipo de contenedor, resumidos en la Tabla 1, el primero morfológico funcional, considerando las características señaladas por Menacho (2007): la transportabilidad, la receptividad, y atributos propios de la clase a la que pertenece la pieza. La transportabilidad es la capacidad que tiene una pieza de ser movilizada de un lugar al otro sin romperse, y su límite está registrado en un máximo de 15 litros por el autor mencionado. El índice de receptividad es la relación entre el diámetro máximo y el diámetro de la abertura. Esta característica también permite controlar la capacidad de acceso o manipulación del interior de las piezas (Menacho 2007:151). En este sentido, y siguiendo a Menacho, una baja receptividad evita derrame en el movimiento (valores menores a 0,6 ) y el uso de cerramientos o la pérdida de calor (menores a 0,72 ). Por el contrario, índices mayores (de o,6 a 1) permiten un fácil acceso al interior pero aumentan la posibilidad de pérdida de calor o líquido en el transporte. Los valores intermedios $(0,4$ a 0,8$)$, por su parte, permiten la retención del calor, y a su vez el fácil acceso y manipulación del contenido. Los atributos morfológicos propios, como pueden ser la forma de los labios o la ubicación y la forma de las asas, por ejemplo, pueden ser características más importantes a la hora de manipular la pieza (Rice 1987) si ésta está caliente, si es pesada o difícil de apoyar.

Segundo, los análisis químicos, junto con los análisis tecnomorfológicos propuestos anteriormente, fueron una vía de información más para la caracterización cerámica

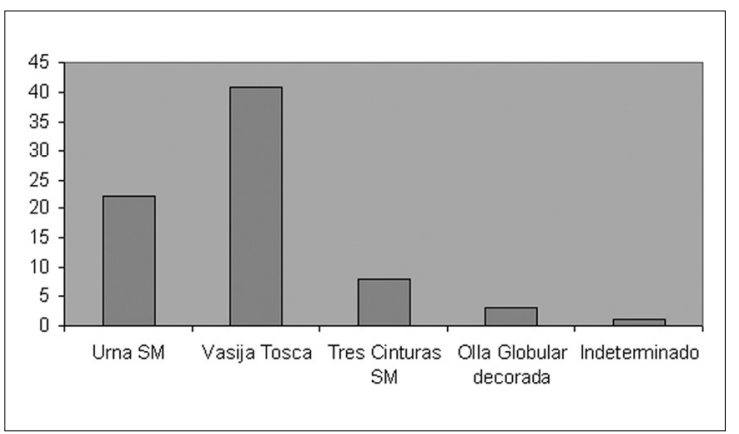

Figura 4. Distribución del tipo de vasijas utilizadas para los enterratorios. 
(Cañabate Guerrero y Sánchez Vizcaíno 1995). La búsqueda y la identificación de lípidos se realizó utilizando la técnica de cromatografía de gases acoplada a espectrometría de masas (CG-EM) sobre siete piezas que pudieron ser intervenidas.

A continuación veremos los resultados para cada tipo cerámico ${ }^{6}$ :

Vasijas toscas. Estas piezas presentan formas subglobulares de contorno inflexionado (Shepard 1957), con dos asas verticales ubicadas en la mitad del cuerpo de la pieza (Figura 2a). La superficie externa de todas las piezas registradas fue trabajada con un peine sobre la arcilla fresca y alisada en su interior. Es difícil estimar si este tratamiento es puramente ornamental o guarda alguna relación con el uso de la cerámica. Otra característica es un cuello corto que finaliza en un borde evertido. De las piezas observadas, solo cuatro no conservan aún hollín en sus paredes exteriores, lo que indica que la mayoría estuvieron expuestas al fuego. Las bases cónicas de estas piezas, según la observación etnográfica (Randall 1993), pueden ser enterradas en la tierra para estabilizarlas en las superficies planas, de esta manera las afianzan para que no vuelquen en el centro de los fogones.

Los resultados obtenidos, sintetizados en la Tabla 1, nos permiten decir que las vasijas toscas además de ser utilizadas como contendores para entierros, tuvieron usos previos y no excluyentes relacionados con la cocción y el acopio de alimentos. Lo primero evidenciado, como ya vimos, por la presencia de hollín, junto con la receptividad media que impide la rápida perdida de calor, pero habilita la manipulación en el interior de la pieza. Otra evidencia que respalda su uso culinario es la identificación de lípidos en los análisis químicos (Amuedo 2012:285-286), con la individualización de algunos de los recursos implicados en cocción y/o almacenamiento. Entre éstos se destaca la presencia de ácidos grasos ramificados, que sugieren la posibilidad de estar frente a grasas de rumiantes como camélidos (Com. personal Maier 2010), trazas de aceites vegetales, como maíz (Zea mays),y ácidos asociados a leguminosas como el chocho o tarwi (Lupinussp.) y a la presencia de cera de abejas. La cera de abeja puede responder al almacenamiento en su interior o muy posiblemente a su uso como sellamiento de las paredes de la vasija. Por otro lado, los análisis preliminares de microrestos vegetales sobre algunas piezas arrojaron la presencia de almidones de algarrobo (Prosopissp.) y poroto (Phaseolusvulgaris), no detectado en los análisis químicos.

El uso de estas vasijas como depósitos se sugiere por las condiciones como fueron halladas (véase Figura 3): en grupos dentro de los recintos, cercanas a los muros, con las bocas emergiendo del piso de ocupación con tapas hechas con pucos, restos de ollas o conanas (morteros), muchas veces con restos de alimentos en su interior, en las mismas condiciones de hallazgo que los entierros de infantes.

Urnas santamarianas. En cuanto a su morfología, las urnas santamarianas se corresponden con las formas restringidas independientes (Shepard 1957), ya que el diámetro de la boca de la pieza es independiente de su diámetro mayor (Marchegiani 2008). La estructura está compuesta por dos secciones: el cuello y el cuerpo, propiamente dicho (véase Figura 2 b). Las superficies externas e internas están alisadas, presentando baños de color blanco o rojo sobre los que se pinta con color negro, la mayoría de las veces, y en otros casos con rojo. Los diseños y la iconografía presente en estas piezas es bien conocido en la bibliografía de la zona y el valle Calchaquí en general (Caviglia 1985; Marchegiani 2008; Nastri 2008), y no es parte de esta investigación ahondar en su interpretación.

Los análisis sobre este tipo cerámico muestra en un principio la falta de hollín, lo cual nos habla de una relación con los alimentos que excluye la cocción. Los resultados arrojados por los análisis químicos muestran resultados similares a los comentados para las vasijas toscas, lo que puede ligarlas al acopio de alimentos en su interior. Además, los resultados preliminares de microrestos sobre urnas santamarianas muestran una gran abundancia de almidones de tubérculos con marcas de molienda. Resultados que deben seguir siendo analizados, pero podría indicar que algunos recursos no detectados en los lípidos pudieron ser alojados en su interior, como harinas de tubérculos, por ejemplo.

Puede considerarse la posibilidad de transporte de recursos en su interior si la pieza no fue saturada de contenido,

6 Para más detalles de los estudios realizados ver Amuedo 2012. 
ya que la pieza completa supera los 27 litros de capacidad contra los 15 litros de límite. La ubicación de las asas encintadas en la parte inferior y de forma horizontal hace pensar en la búsqueda de una distribución del peso que evite su colapso al ser movilizada con peso. A su vez, los contextos también evidencian su uso como depósito.

No se descarta la posibilidad de la preparación de alimentos o bebidas en su interior, debido a abrasión observada en algunas piezas, como también el descascaramiento de las paredes internas, como se observa en las vasijas utilizadas para fermentar chicha (Gastaldi 2010:213).

Urnas santamarianas de "tres cinturas". En cuanto a su morfología pertenecen a la clase estructural restringida independiente (Shepard 1957). Siguiendo a Baldini (1980), estas piezas tienen características similares a las santamarianas, pero tienen un contorno complejo con más de una entrada. Las tres entradas presentes en el contorno, también conocidas como "cinturas", delimitan secciones horizontales en el cuerpo de la pieza (Figura 2c). Las superficies externas e internas se muestran alisadas, presentando decoración en todo el exterior y en el interior solo en los bordes.

Otra de las características es la ubicación de las asas entre los límites de la última sección y la segunda sección horizontal, y apéndices en la parte superior del cuello en forma de trenzas puestas de forma vertical. Éstos pueden estar presentes o no en los cuellos.

Para este tipo de contenedor, siguiendo los resultados de la Tabla 1, se interpreta una situación similar a la establecida para las urnas santamarianas, ya que las diferencias observadas en sus atributos físicos no afectan sus posibles funciones para transporte y acopio de alimentos.

Ollas globulares decoradas. Las vasijas analizadas son globulares de contorno inflexionado (Shepard 1957). La superficie externa de la vasija registrada se presenta alisada, y al igual que los registros de La Paya, esta se encuentra "...pintada con un fondo blanco; con grandes líneas negras, formando grandes ángulos..." (Ambrosetti 1907:234) (Figura 2d). No se observa este tipo de ornamentación en el resto de la cerámica santamariana. Otra característica presente es un cuello corto que finaliza en un borde evertido.
A diferencia de las vasijas toscas, tiene asas horizontales, ubicadas en la mitad del cuerpo de la pieza. Esta ubicación posiblemente ayudaba a una mejor distribución del peso si la pieza debía cambiarse de lugar, evitando su colapso con movilizaciones mínimas, dado el gran tamaño y peso con contenido en su interior (de 93 litros promedio). Las bases cónicas, al igual que las vasijas globulares toscas, solo permitirían una mayor estabilidad de la pieza si estás eran enterradas, encastrándolas en las superficies lisas. Las dimensiones, como se mencionó más arriba, superan ampliamente las de los otros contenedores cerámicos, por lo que considero que la función previa sugerida por la evidencia es la de depósito para acopio o para la preparación de bebidas, descartando sus funciones culinarias por la ausencia de hollín.

A manera de resumen, podemos observar como los cuatro tipos de contenedores cerámicos utilizados en los contextos mortuorios pudieron ser parte de otras actividades ligadas a tareas domésticas. Más adelante retomaremos la discusión de este punto.

\section{Rango etario considerado en la práctica mortuoria}

Como ya se adelantó, los niños a los que se les practicaba este tipo de inhumación eran menores de tres años según la muestra analizada, aunque no debemos descartar variaciones considerando otros hallazgos aun inéditos. En su gran mayoría, fueron inhumados individualmente dentro de los contenedores cerámicos, en contraste con lo ocurrido en los entierros de adultos en su mayoría múltiples, y de manera completa (Acuto et al. 2011:34), aunque hay tumbas de infantes constituidas solo por cráneos (nueve dentro de un universo de 75).

Existen tres métodos conocidos para determinar la edad esqueletal de los subadultos: el desarrollo dental y erupción dental, el tamaño de los huesos y los centros de osificación, y los que evalúan el proceso de aparición y fusión de los centros de osificación (Rissech 2008). El primero de estos métodos, el de desarrollo dental, es el más adecuado para los individuos subadultos ya que es preciso y constante en los primeros años de vida. El segundo método, basado en los ritmos de crecimiento, tiene en cuenta el tamaño de cada elemento óseo según diferentes edades. Estos índices pueden ser afectados tanto por estrés ambiental a nivel individual o poblacional, como por 
variables genéticas (Stinson 2000). Siguiendo a Rissech (2008), los elementos diagnósticos más utilizados por su alta conservación y facilidad de cálculo son: el coxal, la escápula y el fémur. En este caso se utilizó, por ser los mejor conservados, el húmero y el fémur. Por último, el tercer método relacionado con la maduración esquelética tiene en cuenta la aparición, morfología y fusión de los centros de osificación de los elementos óseos. En esta investigación se empleó para calcular la edad fetal y perinatal hasta los 2,5 años el método de Weaver (1979 en Scheuer y Black 2000; Rissech 2008). Este método permite precisar una edad estimativa a través del desarrollo del temporal.

Estos tres métodos se utilizaron en la muestra examina$\mathrm{da}$, aunque no todos pudieron ser aplicados en conjunto sobre cada individuo, dado el mal estado de conservación en el que se encuentra la mayor parte de la muestra?

A través del método de desarrollo dental de Ubelaker (1978 en Scheuer y Black 2000) se pudo estimar la edad de 12 individuos de los 19 analizados (Amuedo 2010: 126). La distribución de las edades representa un grupo menor a tres años, si no consideramos el margen de error contenido para el grupo de dos años de +- ocho meses.

La estimación de la edad a partir del tamaño de los huesos se realizó tomando la longitud de aquellos mejor conservados y de forma completa. Se utilizaron las tablas de longitud para fémur y húmero como referencia presentes en Scheuer y Black (2000). Así, de los 19 individuos que integran la muestra solo pudieron ser analizados a través de este método nueve que conservaron de manera completa algún fémur y/o húmero. Cuatro de los individuos

7 Se analizaron un total de 14 entierros de los 75 considerados en la muestra general, los que sumaron un total de 19 cuerpos. De estos, cinco entierros corresponden al sitio Mariscal con un total de ocho individuos. Del sitio Tero se analizaron los cuerpos de siete entierros con nueve cuerpos individualizados. Y por último, se tomó un entierro con un solo cuerpo de La Paya. No se cuenta con material osteológico de la muestra general de 75 entierros, ya sea por la mala conservación que sufre el material óseo en la zona, como por la falta de recuperación del material osteológico de subadultos dentro de los métodos de excavación empleados a principios del siglo XX por Ambrosetti (1907) y Debenedetti (1908). Dentro de esta muestra de 19 individuos se incluye los datos obtenidos por Baffi del entierro de Ruíz de los Llanos (Baffi et al. 2001). solo pudieron analizarse bajo este método, sin poder contrastar con otros elementos diagnósticos. En los cinco restantes pudieron compararse las estimaciones de la longitud de los elementos óseos con aquella determinada a partir de la evidencia dental. El contraste observado entre los resultados permite sugerir la posibilidad de algún evento de estrés metabólico sistémico y/o nutricional, apoyado por la evidencia en seis casos de criba orbitaria ${ }^{8}$. Esta evidencia apoya la posibilidad de que el desfase entre el desarrollo de la edad dental, pautada genéticamente, y el crecimiento del esqueleto postcraneal, afectado por variables ambientales, se deba a un estado de estrés nutricional sufrido por los individuos ${ }^{9}$.

Por el desarrollo del temporal se han analizado siete individuos, de los cuales cuatro pudieron compararse con otros parámetros para afinar la estimación de la edad. En algunos casos, la edad determinada por este método difería notoriamente de la dental. Por la amplitud de los rangos establecidos para la edad del desarrollo del temporal - dividido en cuatro estados entre nacimiento, seis meses, un año y dos años y medio (Rissech 2008)-, puede producirse esta diferencia a la que salvamos a favor de la edad dental por estar genéticamente determinada (Baldini y Baffi 2007a).

Por lo tanto, y realizando las salvedades relacionadas con la falta de los mismos indicadores para cada individuo analizado y apoyándonos en aquellos más efectivos, como la edad dental, hemos podido estimar que el rango de edad de la muestra analizada presenta la distribución observada en la Figura 5. Este rango se asocia con la categoría de infancia, definida dentro de las categorías del desarrollo ontogenético humano (Baffi y Baldini 2007a). El período infantil trascurre desde el comienzo de la vida extrauterina hasta la erupción de los segundos molares

8 En general, son el resultado de anemia por déficit de hierro, la cual puede ser causada tanto por problemas nutricionales como por factores no dietarios, como por ejemplo el bajo peso al nacer, hemorragias, diarrea crónica, infecciones, parásitos, bacterias, etc. (Stuart-Macadam 1989, 1991). En la mayoría de los casos ésta se muestra en las paredes de las órbitas.

9 Ante la carencia de nutrientes, la primera respuesta del cuerpo es la lentificación del crecimiento, y en casos severos la detención de éste (Baffi y Torres 2000). 


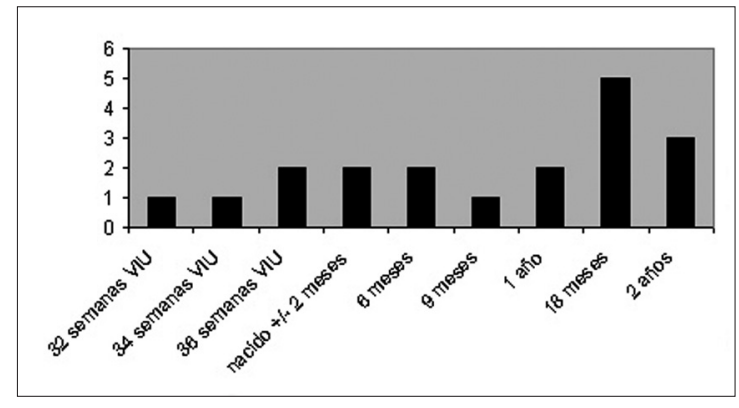

Figura 5. Rango etario asociado a los contextos mortuorios.

de leche, durante los dos primeros años de vida. También, estimando que existen escasas posibilidades que los individuos con menos de 36 semanas de gestación (o vida intrauterina, VIU) hayan podido nacer con vida o sobrevivir en el pasado, se considera la categoría de neonatos o mortinatos para cuatro de los casos analizados.

En el caso de los entierros de infantes, éstos muestran una clara separación del resto de los subadultos y adultos, inhumados dentro de cistas con el mismo tratamiento mortuorio (Amuedo 2010: 141). Si bien se trata de una muestra pequeña ${ }^{10}$, la revisión del contexto de estos subadultos mayores no muestra diferencias con los adultos, razón por la cual no podemos hablar de una materialización en la muerte de otra categoría asociada a la edad. Éstos fueron inhumados ya sea individualmente, o con otros adultos y niños. En el caso de la Sepultura 97 (1907: 181) y 140 (1907: 229), Ambrosetti interpreta que se trata de un niño de 10 o 12 años y otro un poco más pequeño. Para el resto de los hallazgos, menciona que son niños, sin estimar su edad. Sin embargo, debemos destacar sí las menciones sobre la edad de los depositados en vasijas, donde en muchos casos se menciona la posibilidad de niños muertos al poco tiempo de nacer (Ambrosetti 1907: 221). Por otro lado, es valioso mencionar que tanto Eric Boman para el valle Calchaquí (1991 [1908]: 155-157), como Eduardo Cigliano para Tastil (1973: 95), sostienen que la práctica de entierro en urnas en momentos del período Intermedio Tardío estuvo destinada exclusivamente a párvulos, deteniéndose en el de-

10 Sepulcros 40, 97, 140 y 196 de La Paya (Ambrosetti 1907), en los que halló restos de niños mayoresdentro de cistas, algunos de ellos acompañados por adultos. Del sitio Tero se destacan los entierros $\mathrm{E}_{47}$ y E50 excavados por Díaz. talle de los dientes de los individuos observados, muchos de los cuales no habían salido de sus alveolos.

A través de esta determinación, siguiendo la evidencia disponible, más las citas de los trabajos pioneros en el área, podemos preguntarnos si estas tumbas nos hablan de una categoría etaria particular, y si los contextos analizados pudieron ser parte de dinámicas transformacionales necesarias para la constitución de los individuos fallecidos antes de ser sujetos plenos. Debemos considerar que la heterogénea y actual clasificación etaria moderna en generaciones persigue objetivos imbricados directamente con nuestra inserción histórica (Baxter 2005) y no son de naturaleza transhistórica.

\section{Sobre las vasijas y su consustación en la vida do- méstica}

De lo visto anteriormente, es posible determinar diferentes actividades en las que pudieron utilizarse los elementos estructurantes de las tumbas, tanto contenedores cerámicos y tapas:

-Transporte de alimentos en urnas santamarianas y urnas santamarianas de "tres cinturas". Si bien hace falta más investigación sobre esto, considero que un elemento interesante a tener en cuenta es la poca capacidad de las urnas en relación al resto de las vasijas, la ubicación de las asas encintadas en la parte baja de cuerpo de manera horizontal y la evidencia de restos de lípidos asociados a grasa de rumiantes, lípidos vegetales y cera de abeja (Amuedo 2010:95).

-Almacenamiento en silos domésticos por medio de vasijas toscas, urnas santamarianas y ollas globulares decoradas. Por lo general, en grupos cercanos a los muros de las casas o patios, enterradas y con las bocas emergiendo de los pisos de ocupación, tapadas con pucos, conanas o restos de vasijas.

-Preparación de alimentos o bebidas en urnas santamarianas y ollas globulares decoradas. Se han observado marcas de abrasión mecánica en el interior de las piezas, como también posibles huellas de descascaramiento como el producido en las vasijas donde se fermenta chicha También la presencia de lípidos asociados a maíz. Los análisis de micro-restos vegetales en desarrollo podrán 
darnos más información sobre esta actividad.

- Cocción en vasijas toscas, evidenciado en los restos de hollín presentes en la superficie externa.Por otro lado, se han hallado evidencia de lípidos asociados a ollas toscas como: grasa de rumiantes, maíz, maní, poroto blanco y miel.

Además los contextos mortuorios estaban estructurados con elementos que aluden a otras actividades desarrolladas en los mismos espacios:

-Molienda representada por las conanas utilizadas como tapas.

-Consumo de los alimentos evidenciado por la presencia de pucos para tapar tanto los silos como las tumbas.

-Entierro de infantes en vasijas toscas, urnas santamarianas, urnas santamarianas de "tres cinturas" y ollas globulares decoradas. Todas fueron utilizadas para inhumar dentro de los espacios domésticos, en los mismos lugares donde fueron halladas los mismos tipos de vasijas en las mismas condiciones, pero sin restos humanos en su interior.

La imagen que se nos presenta de los elementos expuestos son habitaciones con ollas enterradas en los centros de los fogones, estabilizadas por sus bases cónicas. Almacenes junto a los muros, cubiertos con conanas, pucos o restos de ollas rotas, que pudieron ser removidos para utilizarlos respectivamente en la molienda, para servir comida o para tostar granos al rescoldo de los fogones. Además, otras vasijas pudieron estar sobre la superficie del piso almacenando algún tipo de bebida o harina, otras fermentando en algún rincón oscuro de la casa. Todos esos elementos, por otro lado, no son exclusivos de cada actividad, sino que los tenemos que pensar circulando en varias tareas.

De esta imagen se desprenden las siguientes reflexiones: ¿qué tipo de estatus ontológico es creado a lo largo de la historia de las piezas, que no solo las haga rotar de actividad sino que las anule para seguir participando de otras? La etnografía andina y mis propias observaciones etnográficas arrojan ejemplos donde la cocción anula la capacidad de fermentación de una olla (Com. personal Pazzarelli 2013), o la molienda de un grano anula la posibilidad de que otro sea molido en el mismo mortero porque arruina los preparados. En este sentido, ¿cómo están direccionados los esfuerzos de estas piezas en la transformación de ciertos alimentos para culminar en una actividad que anula seguir participando del resto de las anteriores, como es la contención de los restos humanos de infantes?

\section{La sociabilización de los seres incompletos}

A través de los análisis expuestos hemos podido observar que en el caso de los contextos mortuorios de infantes norcalchaquíes nos encontramos con dos elementos con recorridos biográficos diferentes dentro de la comunidad. Por un lado, las vasijas, como otros elementos estructurantes, participaron de múltiples actividades domésticas donde estuvieron vinculadas personas jóvenes y adultas, como la cocción de alimentos o el almacenamiento dentro de las casas, antes de formar parte de la tumba. Según observaciones etnográficas en la zona, las vasijas cerámicas de cocina solían tener una larga vida útil, una de las razones pudo ser que las ollas viejas dan mejor sabor a las comidas (Fríes 2004: 124; Pazzarelli 2009). Las mismas vasijas pudieron tener amplias trayectorias dentro de los grupos familiares, superando varias generaciones. Aun así, dentro del contexto arqueológico, vasijas sin roturas y con posibilidades de haber hecho más sabrosas las comidas dejan de usarse para cocinar y son usadas como silos de almacenamiento o para inhumar niños.

Esto pudo estar relacionado con la capacidad de las vasijas de condensar grados de subjetividad en cada una de sus participaciones. Ellas pudieron transformarse en pares de los demás sujetos participantes del espacio doméstico, personas y objetos como sujetos plenos. La proximidad con las prácticas y la participación activa en la transformación de alimentos o bebidas en su interior moldearon sus cuerpos, a través de marcas, como el hollín y la abrasión. Tal y como el cuerpo de los humanos reciben marcas. Además, estas marcas y usos anularon las posibilidades de ser usadas en varias funciones al mismo tiempo, como forma de estabilizar o anular ciertas capacidades agentivas de las ollas, redireccionando sus "esfuerzos" (sensu Cavalcanti-Schiel 2007).

A su vez, todas las actividades hechas carne en las vasijas a través de sus usos se desplegaron activamente en los 


\begin{tabular}{|c|c|c|c|c|c|}
\hline \multirow{2}{*}{\multicolumn{2}{|c|}{ Análisis macroscópicos y microscópicos }} & \multicolumn{4}{|c|}{ Contenedor cerámico } \\
\hline & & \multirow{2}{*}{$\begin{array}{c}\text { Vasijas toscas } \\
23,1 \mathrm{~cm}\end{array}$} & \multirow{2}{*}{\begin{tabular}{|c|} 
Urnas santamarianas \\
$24,42 \mathrm{~cm}$
\end{tabular}} & \multirow{2}{*}{$\begin{array}{c}\text { Urnas santamarianas } \\
\text { tres cinturas } \\
24,5 \mathrm{~cm}\end{array}$} & \multirow{2}{*}{$\begin{array}{c}\text { Ollas globulares decoradas } \\
28 \mathrm{~cm}\end{array}$} \\
\hline \multirow{6}{*}{$\begin{array}{l}\text { Características } \\
\text { dimensionales } \\
\text { (promedios) }\end{array}$} & Diámetro boca & & & & \\
\hline & Diámetro máximo & $38,2 \mathrm{~cm}$ & $27,1 \mathrm{~cm}$ & $31 \mathrm{~cm}$ & $60,5 \mathrm{~cm}$ \\
\hline & Diámetro base & $10 \mathrm{~cm}$ & $11,5 \mathrm{~cm}$ & $10 \mathrm{~cm}$ & - \\
\hline & Altura & $47,8 \mathrm{~cm}$ & $53 \mathrm{~cm}$ & $40 \mathrm{~cm}$ & $60 \mathrm{~cm}$ \\
\hline & Volumen & 43,361 & 13,251 & 25,651 & 93,721 \\
\hline & Receptividad & 0,57 & 0,945 & 0,88 & 0,46 \\
\hline \multicolumn{2}{|c|}{ Atributos morfológicos propios } & $\begin{array}{l}\text { Bases cónicas y asas } \\
\text { verticales en la mitad } \\
\text { de los cuerpos. }\end{array}$ & $\begin{array}{l}\text { Largos cuellos con } \\
\text { diámetros máximos y } \\
\text { asas horizontales. }\end{array}$ & $\begin{array}{c}\text { Las tres entradas que } \\
\text { delimitan secciones } \\
\text { horizontales. Asas entre la } \\
\text { última y segunda sección } \\
\text { horizontales. }\end{array}$ & $\begin{array}{c}\text { Asas en la parte inferior del cuerpo } \\
\text { y de manera horizontal. Gran } \\
\text { tamaño. }\end{array}$ \\
\hline \multicolumn{2}{|c|}{ Alteraciones observables } & $\begin{array}{c}\text { Hollín en la } \\
\text { superficie externa }\end{array}$ & $\begin{array}{l}\text { Remoción de material en } \\
\text { el fondo de la pieza. }\end{array}$ & - & - \\
\hline \multicolumn{2}{|c|}{ Análisis químicos } & $\begin{array}{l}\text { Grasas de } \\
\text { rumiantes. Vegetales } \\
\text { (maíz, maní, tarwi). } \\
\text { Cera de abeja. }\end{array}$ & $\begin{array}{l}\text { Grasas de rumiantes. } \\
\text { Vegetales (maíz, maní). } \\
\text { Cera de abeja. }\end{array}$ & - & - \\
\hline \multicolumn{2}{|c|}{ Microrestos vegetales } & $\begin{array}{l}\text { Algarrobo, maíz, } \\
\text { porotos. }\end{array}$ & Algarrobo, tubérculos. & - & - \\
\hline
\end{tabular}

Tabla 1. Síntesis de los resultados obtenidos de los análisis mencionados.

mismos espacios donde fueron depositadas junto con los cuerpos. Las vasijas estuvieron consustanciadas con la vida social próxima e íntima del poblado. Participaron, invirtiendo esfuerzos en los procesos, y acompañaron a los otros agentes dentro de las actividades, se embebieron en ellas, en sus espacios. Como ocurre con muchas ollas de uso actual, donde su vínculo con los humanos es tan fuerte que hasta se les pone nombres y se conversa con ellas mientras se cocina (Fríes 2004).

El otro de los elementos son los restos mortuorios de los infantes inhumados en el interior de aquellas vasijas. La evidencia nos muestra que durante los momentos tardíos, los niños menores de tres años tuvieron un tratamiento mortuorio diferencial al resto de los individuos. Pareciera que los infantes y los niños mayores fueron dos categorías etarias disímiles, con un tratamiento diferente en el momento de su muerte.

Actualmente, los infantes, los niños andinos que no pueden participar en las actividades reproductivas de la comunidad son considerados como seres en proceso de formación. No es la intensión trazar una analogía directa entre los trabajos etnográficos y el pasado calchaquí, sin embargo, los trabajos sobre comunidades actuales nos permiten reflexionar acerca de la categoría moderna de la infancia, mucho más romántica que la de las poblaciones altiplánicas contemporáneas. La visión de este período de la vida como una etapa de inestabilidad y peligrosidad para la comunidad es sumamente interesante para pensar la infancia en el pasado y sobre la necesidad de conservar dentro de las estructuras y ritmos domésticos los cuerpos de los niños.

Los niños preinkas fallecidos en momentos tempranos de sus vidas en el valle Calchaquí Norte no completaron su ingreso a la comunidad, las vasijas sí. Los cuerpos humanos no determinaron la humanidad de los niños, las marcas en los cuerpos de las vasijas las transformaron en personas. 


\section{$*$ Conclusión}

Considero que este trabajo es un punto de partida interesante para pensar la construcción de la subjetividad en el pasado, aunque deben ser aportados más datos dentro de este esquema de integración entre objeto-objeto y objetosujeto. En el caso de las prácticas mortuorias del valle Calchaquí Norte, los sujetos menores de tres años difícilmente pudieron realizar tareas domésticas o sobre la tierra, como el cultivo, ya que a esa edad algunos se mueven con poca sincronización, no saben hablar o lo hacen con dificultad y son muy pocas sus habilidades manuales. Esto no es más que parte del desarrollo ontogénico de los individuos, pero aun así no permitió una integración completa a la vida del poblado del que formaron parte. Cada actividad para la reproducción de la vida implicó un despliegue de energía e inversión de esfuerzos, tanto de humanos como de no humanos. Los infantes no participaron activamente en este ciclo, solo pudieron hacerlo aquellos que se constituyeron como personas completas dentro de las acciones de la comunidad, no solo humana sino aquella universal.

En el momento de su muerte estos individuos, incompletos dentro de su integración a la comunidad, y por ello inestables, fueron depositados envueltos dentro de una materialidad embebida en las prácticas sociales domésticas: las vasijas y las casas. En ellas se desarrollaron las actividades de transformación de los alimentos, entre otras como el descanso, la alimentación, la producción de herramientas, etc. En este sentido es posible pensar que las vasijas no fueron simples representaciones de aquellas actividades, sino que en tanto participantes activos en la conformación de la vida cotidiana y la reproducción de la comunidad, pudieron controlar luego de su conformación en sujetos socialmente completos, la inestabilidad y el peligro en el momento de la muerte de un ser incompleto dentro del espacio doméstico.

Como bien se dijo al comienzo, se trata de un mundo plagado de singularidades dentro de un esquema relacional, que ofrece además un horizonte moral sobre el que las prácticas de todos los seres se despliegan (Descola 2012:514). En este contexto, los objetos como entidades son parte constituyente de la comunidad, una comunidad ampliada en las que humanos y no humanos participan y comparten un mismo estatus ontológico.

Agradecimientos Agradezco de corazón el apoyo brindado por Félix Acuto en la dirección de esta investigación. También quiero agradecer a Paula Miranda por la bibliografía y consulta constante. Especialmente a Francisco Pazzarelli, Ben Alberti y Magdalena García quiero agradecerles por la lectura del borrador previo y sus sustanciosos aportes. A Henrik Lindskoug por el golpe de gracia en el resumen. Por último, a Helena Horta por su confianza, apoyo y generosidad. Sus sugerencias han sido fundamentales para nutrir este escrito. Sin embargo, los errores, omisiones o torpezas presentes son de mi entera responsabilidad.

\section{* Referencias Citadas}

ACUTO, F. 2008. Materialidad, espacialidad y vida social: Reinterpretando el Periodo Tardío de los Andes del Sur. En Sed Non Satiata II: Acercamientos sociales en arqueología latinoamericana, F. Acuto y A. Zarankin (Eds.), pp. 157-192. Encuentro Grupo Editores, Córdoba.

ACUTO, F., M. KERGARAVAT y C. AMUEDO. 2011. Experiencia de la muerte y la representación de las personas en las prácticas funerarias del Valle Calchaquí Norte. Comechingonia 14: 23-54.

ALBECK, M. E. y M. A. ZABURLÍN. 2007. Lo público y lo privado en Pueblo Viejo de Tucute. En Procesos sociales prehispánicos en el sur andino. La vivienda, la comunidad y el territorio, A. Nielsen (Ed.), pp. 163-181. Editorial Brujas, Córdoba.
ALBERTI, B. 2007. Destabilizing meaning in anthropomorphic vessels from northwest Argentina. Journal of Iberian Archaeology 9/10: 209-230.

ALLEN, C.1998. When Utensils Revolt: Mind, Matter, and Modes of Being in the Pre-Columbian Andes. Anthropology and Aesthetics 33:18-27.

2008. La coca sabe: coca e identidad cultural en una comunidad andina. Editorial CBC: Centro de Estudios Regionales Andinos Bartolomé de las Casas, Cuzco.

AMBROSETTI, J. B.1907. Exploraciones arqueológicas en la ciudad prehistórica de La Paya (Valle Calchaquí, Prov. de Salta). Revista 
de la Universidad de Buenos Aires VIII: sección Antropología 3. Facultad de Filosofía y Letras, Buenos Aires.

AMUEDO, C. 2010. La muerte de niños y su tejido de materialidad: Prácticas, representaciones y categorías construidas en las tumbas de infantes en vasijas Período Tardío (900-1470 DC) Valle Calchaquí Norte. Tesis para optar por el grado de Licenciada en Antropología. Facultad de Filosofía y Letras, Universidad de Buenos Aires.

2012. La conexión entre las prácticas mortuorias de infantes y los alimentos: la materialidad y los significados generados en el movimiento cotidiano. En: Las manos en la masa. Arqueologías y Antropologías de la alimentación en Suramérica, P. Babot, M. Marschoff, F. Pazzarelli (Eds.), pp. 673-698. IDACOR-UNC, Córdoba.

2014. Las sendas de las plantas: conexiones entre el paisaje, la historia, humanos y no-humanos en El Algarrobal (Dpto de Cachi, Salta). Tesis para optar por el grado de Magister. Universidad Católica del Norte-Universidad de Tarapacá.

ARNORLD D. y J.D. YAPITA. 2002. Las wawas del Inka: hacia la salud materna intercultural en algunas comunidades andina. ILCA, La Paz, Bolivia.

BAFFI I., L. BALDINI y R. PAPPALARDO. 2001. Entierro de párvulo en urna. Ruiz de los Llanos (Valle Calchaquí, Salta, Argentina). Boletín Museo de Arqueología y Antropología 4(3): 69-75.

BAFFI I. y M. F. TORRES. 2000. Introducción al estudio de poblaciones extinguidas. Ficha de cátedra publicada por OPFyL. FFyL. Universidad de Buenos Aires.

BALDINI, L.1980. Dispersión y cronología de las urnas de tres cinturas en el Noroeste argentino. Relaciones XIV(1): 49-61.

BALDINI, L. y I. BAFFI. 2003. Niños en vasijas. Entierros tardíos en el Valle Calchaquí (Salta). Runa 24: 43-62.

2007a. Aportación al estudio de prácticas mortuorias durante el período de desarrollos regionales: entierros en vasijas utilitarias del sector central del valle Calchaquí (Salta, Argentina). Revista Española de Antropología Americana 37(1): 7-26.

2007b. Muertos y vivos. Comportamiento mortuorio de las sociedades del Valle Calchaquí Central (Provincia de Salta, Argentina) durante el período de desarrollos regionales. En Memorias Anthropos 2007, pp. 1-11. [Presentado en] Primer Congreso Iberoamericano de Antropología, La Habana.

BASTIEN, W. J.1996. La Montaña del Cóndor. Editorial Hisbol, La Paz.

BAXTER, J. E. 2005. The archaeology of childhood: Children, gender and material culture. Altamira Press, Walnut Creek, California.
BOLIN, I. 2006. Growing up in a Culture of Respect: Child Rearing in Highland Peru. University of Texas Press, Austin, Texas.

BOMAN, E. 1991 [1908]. Antigüedades de la región andina de la República Argentina y del desierto de Atacama. Tomo I, Universidad Nacional de Jujuy.

CAÑABATE GUERRERO, M. L. y R. SÁNCHEZ VIZCAÍNO. 1995. Análisis de indicadores bioquímicos del contenido de recipientes arqueológicos. Complutum 6: 281-291.

CAVALCANTI-SCHIEL, R.2007. Las muchas naturalezas de los Andes. Periferia 7: 1-11.

CAVIGLIA, S. 1985. Las urnas para niños de los valles Yocavily Calchaquí. Su interpretación sobre la base de un enfoque gestáltico. Seminario de Arqueología, Buenos Aires. Ms.

CIGLIANO, E. 1973. Tastil, una ciudad preincaica argentina. Ediciones Cabargón, Buenos Aires.

DEBENEDETTI, S. 1908. Excursión arqueológica a las ruinas de Kipón (Valle Calchaquí, provincia de Salta). Publicaciones de la Sección Antropológica 4.

DEMARRAIS, E. 2001. Mortuary Practices and Political Integration in the Andes: Potentials and Limits of Material Display. 66 th Annual Meeting of the Society for American.

DESCOLA, P. 2006. Beyond nature and culture. Proceedings of the BritishAcademy 139: 137-155.

2012. Más allá de naturaleza y cultura. Amorrortu editores, Buenos Aires.

DÍAZ, P. P. 1978-84. Diario de la excavación realizada en el sitio Tero SSalCac 14. Informe depositado en el Museo Arqueológico de Cachi, Salta.Ms.

1981. Diario de la excavación realizada en el sitio La Paya SSalCac 1. Informe depositado en el Museo Arqueológico de Cachi, Salta. Ms.

EARLS, J. y I. SILVERBLATT.1978. La realidad física y social en la cosmología andina. Actes du XLII Congrès International des Américanistes: Congres du centenaire 4: 299-326.

FERNÁNDEZ, G. 2002. Aymaras de Bolivia: entre la tradición y el cambio cultural. Ediciones Abya-Yala, Quito.

FINLAY, N. 2009. Outside of Life: infant burials from cillin to cist. World archaeology 31(3): 407-422.

FRÍES, A. M. 2004. Sabores y saberes: comida campesina andina, A. 
Fríes (Ed.). Proyecto Andino de Tecnologías Campesinas (PRATEC), Lima.

GASTALDI, M. 2010. Cultura material, construcción de identidades y transformaciones sociales en el Valle de Ambato durante el primer milenio $D C$. Tesis para optar por el grado de doctor. Facultad de Ciencias Naturales y Museo Universidad Nacional de La Plata.

INGOLD, T. 2000 . The perception of the environment: essays in livelihood, dwelling and skill. Routledge, Londres.

2010. Footprints through the weather world: walking, breathing, knowing. Journal of the Royal Anthropological Institute $16: 121-139$

JOYCE, R. 2005. Archaeology of the body. Annual Reviews in Anthropology 34: 139-158.

LATOUR, B. 2008. Reensamblar lo social: una introducción a la teoría del actor-red. Editorial Manantial, Buenos Aires.

LE BRETON, D. 2002. Antropología del cuerpo y modernidad. Ediciones Nueva Visión, Buenos Aires.

LEMONNIER, P. 1992. Elements for an Anthropology of Technology. Anthropological Papers 88: 1-24.

LORANDI, A.M. y R. BOIXADÓS. 1987-88. Etnohistoria de los Valles Calchaquíes en los siglos XVI y XVII. Runa XVII-XVIII: 263-419.

MALFOURIS, L.2008. Beads for a Plastic Mind: the 'Blind Man's Stick' (BMS): Hypothesis and the Active Nature of Material Culture. Cambridge Archaeological Journal 18(3): 401-14.

MARCHEGHIANI, M.2008. Estilo y cronología. Los cambios en la cerámica funeraria de Rincón Chico entre los siglos X y XVII DC. En Estudios arqueológicos en Yocavil, M. N. Tarragó y L. R. González (Eds.), pp. 127-175. Asociación de Amigos del Museo Etnográfico, Buenos Aires.

MENACHO, K.2007. Etnoarqueología y estudios sobre funcionalidad cerámica: aportes a partir de un caso de estudio. Intersecciones en Antropología 8: 149-161.

MARTÍNEZ, G.1989. Espacio y pensamiento: Andes Meridionales. Editorial Hisbol, La Paz.

MERLEAU-PONTY, M.1957. Fenomenología de la percepción. Fondo de Cultura Económica, México.

2008 [1948]. El mundo de las percepciones: siete conferencias. Fondo de Cultura Económica, Buenos Aires.
NASTRI, J. 2008. La figura de las largas cejas de la iconografía santamariana: chamanismo, sacrificio y cosmovisión calchaquí. Boletín del Museo Chileno de Arte Precolombino 13: 9-34.

NASTRI, J. y L. STERN. 2011. Cosmología y construcción histórica de la iconografía santamariana. Boletín del Museo Chileno de Arte Precolombino16(2): 27-48.

NIELSEN, A. 2006. Plazas para los antepasados: Descentralización y poder corporativo en las formaciones políticas preincaicas de los Andes circumpuneños. Estudios Atacameños 31: 63-89.

PAZZARELLI, F. 2009. Criar, cosechar, picar, moler, hervir y hacerse: itinerarios de la cocina y la comida en la literatura antropológica sobre los Andes. Informe Final de Estancia de Lecturas, dirigida por la Dra. Denise Arnold, Instituto de Cultura y Lengua Aymara (ILCA). Ms.

PLATT, T. 2002. El feto agresivo: Parto, formación de la persona y mito-historia en los Andes. Estudios Atacameños 22: 127-155.

PODESTÁ, C. y E. PERROTA. 1973. Relaciones entre culturas del Noroeste argentino. San José y Santa María. Antiquitas 17:6-15.

RANDALL, R. 1993. Los dos vasos: cosmovisión y política de la embriaguez desde el inkanato hasta la colonia. En: Borracheray memoria: la experiencia de lo sagrado en los Andes, T. Saignes (Ed.), pp.73-112. Editorial Hisbol e Instituto Francés de Estudios Andinos, La Paz y Lima.

RICE, P. 1987. Pottery analysis: A sourcebook. University of Chicago Press, Chicago.

RISSECH, C. 2008. Nasciturus, infans, puerulus, vovis mater terra. En The death in the childhood, F. Gusi, F. Muriel, C. Olària (Eds). Servicio de Investigaciones Arqueológicas y Prehistóricas, Diputació de Castelló.

SCHEUER, L. y S. BLACK. 2000. Developmental juvenile osteology. Academic Press, San Diego.

SHEPARD, A. 1957. Ceramics for the Archaeologist. Carnegie Institution of Washington, Washington, D.C.

SPEDDING, A. 2008. Religión en los Andes: extirpación de idolatrías y modernidad de la fe andina. Instituto Superior Ecuménico Andino de Teología (ISEAT), La Paz.

STINSON, S. 2000. Growth Variation: Biological and Cultural factors. En Human Biology: An Evolutionary and Biocultural Perspective, S. Stinson, B. Bogin, R. Huss-Ashmore y D. O'Rourke (Eds.), pp. 425-463. Editorial Wiley-Liss, New York. 
STUART-MACADAM, P. L. 1989. Nutritional deficiency diseases: A survey of scurvy, rickets and iron deficiency anemia. En Reconstruction of life from the skeleton, M. Iscan y K. Kennedy (Eds.), pp. 201-222. Editorial Alan R. Liss, New York.

1991. Porotic hyperostosis: changing interpretations. En $\mathrm{Hu}$ man Paleopathology, D. Ortner y A. Aufderheide (Eds.), pp. 36-39. Smithsonian Institution Press, Washington, D.C.

TARRAGÓ, M.1980. Los asentamientos aldeanos tempranos en el sector septentrional del valle Calchaquí y el desarrollo agrícola posterior. Estudios Arqueológicos 5: 29-53.

1994. Jerarquía Social y Prácticas Mortuorias. Actas y Memorias del XI Congreso Nacional de Arqueología Argentina XIII (1/4): 170174. Museo de Historia Natural, San Rafael.
TARRAGÓ, M., M. T. CARRARAy P. P. DÍAZ. 1979. Exploraciones arqueológicas en el sitio SSalCac 14 (Tero), Valle Calchaquí. Antiquitas 2: 231-242.

VAN VLEET, K.2008. Performing Kinship. Narrative, Gender, and the Intimacies of Power in the Andes. University of Texas Press, Austin.

VELANDIA JAGUA, C. 2005. Iconografía funeraria en la cultura Santa María-Argentina. Oficina de Investigaciones y Desarrollo Científico, Universidad del Tolima, Ibagué.

VIVEIROS DE CASTRO, E. 1986. Araweté. Os deuses canibais. Editorial Zahar, Rio de Janeiro.

2010. Metafísicas caníbales: líneas de antropología postestructural. Katz Editores, Madrid, Buenos Aires. 